OPEN ACCESS

Edited by:

Damiana Leo,

University of Mons, Belgium

Reviewed by:

Amy Claire Reichelt,

RMIT University, Australia

Fabrizio Sanna,

Università degli Studi di Cagliari, Italy

*Correspondence:

Pietro Cottone cottone@bu.edu

Specialty section:

This article was submitted to

Neuropharmacology,

a section of the journal

Frontiers in Pharmacology

Received: 14 December 2017

Accepted: 06 February 2018

Published: 27 February 2018

Citation:

Moore $C F$, Sabino $V$ and Cottone $P$

(2018) Trace Amine Associated Receptor 1 (TAAR1) Modulation of Food Reward.

Front. Pharmacol. 9:129. doi: 10.3389/fphar.2018.00129

\section{Trace Amine Associated Receptor 1 (TAAR1) Modulation of Food Reward}

\author{
Catherine F. Moore ${ }^{1,2}$, Valentina Sabino ${ }^{1}$ and Pietro Cottone ${ }^{1 *}$ \\ 1 Laboratory of Addictive Disorders, Departments of Pharmacology and Psychiatry, Boston University School of Medicine, \\ Boston, MA, United States, ${ }^{2}$ The Graduate Program for Neuroscience, Boston University School of Medicine, Boston, MA, \\ United States
}

Eating disorders and some forms of obesity are characterized by addictive-like, compulsive eating behavior which contains numerous similarities with compulsive drug use. Food intake is in part mediated by reward and reinforcement processes that can become dysregulated in these disorders. Additionally, impairments in inhibitory control regulation of reward-related responding can cause or further exacerbate binge and compulsive eating. Dysfunctions in two neurotransmitter systems in the mesocorticolimbic pathway, dopamine and glutamate, are thought to contribute to maladaptive eating behaviors. The trace amine associated receptor 1 (TAAR1) system is a promising therapeutic target for compulsive eating behavior due to the role of TAAR1 in synaptic transmission and in the modulation of dopaminergic and glutamatergic signaling. In support of this notion, the TAAR1 agonist RO5256390 was found to decrease the reinforcing effects of palatable food-cues and to reduce binge-like and compulsive-like eating of palatable food. Additionally, prolonged, intermittent access to palatable food was shown to downregulate TAAR1 in the prefrontal cortex, suggesting a potential role for TAAR1 signaling in inhibitory control processes. Research into the role of TAAR1 in addiction, including TAAR1's ability to modulate psychostimulant reward and reinforcement, bolsters support for TAAR1 agonism as a pharmacological treatment for compulsive eating and other addictive behaviors. This review summarizes the evidence for TAAR1 agonism as a promising therapeutic for compulsive eating behavior as well as the hypothesized mechanism responsible for these effects.

Keywords: binge eating, addiction, compulsive, prefrontal cortex, inhibitory control

\section{INTRODUCTION}

Eating disorders, including binge eating disorder (BED), bulimia nervosa (BN), anorexia nervosa (AN), 'food addiction', and some forms of obesity are associated with significant economic and social costs (Lehnert et al., 2013; Whiteford et al., 2013) and limited effective treatments are available (Flament et al., 2012). A main driver of eating disorders is thought to be the increased availability of highly palatable and highly reinforcing food, rich in fats and sugars, which results in addictive-like overconsumption (Morris et al., 2015). Dysfunctions in dopaminergic and glutamatergic neurocircuitries that mediate reward/reinforcement and inhibitory control processes are hypothesized to drive binge and compulsive eating behaviors (Moore et al., 2017a). The trace amine-associated receptor 1 (TAAR1) system has recently gained attention as a neuromodulator of dopaminergic and glutamatergic signaling, making it a very promising therapeutic target for 
addiction-like disorders. To date, while a multitude of research has investigated the role of TAAR1 in drug addiction (Thorn et al., 2014; Harkness et al., 2015; Pei et al., 2015; Liu et al., 2016), very little is known about the modulatory role of TAAR1 in the rewarding properties of food. The scope of this mini-review is to discuss published studies pertaining to TAAR1 in relation to food reward.

\section{TAAR1 AGONISM BLOCKS BINGE EATING OF PALATABLE FOOD}

Binge eating is defined as consuming large quantities of food in a short period of time accompanied by a loss of control over food intake (American Psychiatric Association, 2013; Davis, 2013b). In a typical binge eating episode, palatable food, usually rich in fats and sugars, is consumed at a very high eating rate. Binge eating is a central feature of $\mathrm{BED}, \mathrm{BN}$, and some forms of $\mathrm{AN}$, and is also highly prevalent in obese individuals (Dingemans and van Furth, 2012; Davis, 2013a). Binge eating is driven largely by hedonic reward mechanisms and results in similar neurochemical consequences as drugs of abuse (Rada et al., 2005; Avena et al., 2008; Cottone et al., 2008; Corwin et al., 2011). Thus, the ability of TAAR1 agonism to reduce psychostimulant reward and to modulate the mesolimbic dopaminergic signaling (Miller et al., 2005; Xie et al., 2007; Espinoza et al., 2015) led to its investigation as a potential therapeutic to decrease binge-like eating of palatable food intake in rodents (Ferragud et al., 2017). The effects of TAAR1 agonism were investigated in a rodent model of binge-like eating induced by limiting access to a highly palatable, sugary diet for $1 \mathrm{~h}$ /day (Ferragud et al., 2017), a paradigm which induces both binge eating and heightened eating rate in rodents. In this study, the selective TAAR1 agonist RO5256390 dose-dependently blocked binge-like eating of the palatable diet. The highest dose of $10 \mathrm{mg} / \mathrm{kg}$ was sufficient to reduce intake of the palatable diet to equivalent levels of standard chow intake in control subjects, which notably was not affected by the drug treatment. Interestingly, selective drug effects on palatable food intake were also observed when the doses of 1 and $3 \mathrm{mg} / \mathrm{kg}$ were injected. Furthermore, treatment with RO5256390 decreased the feeding rate for the highly palatable food.

In a different study, RO5256390 was also able to decrease, as well as slow down, responding for chocolate flavored pellets in rats (Pei et al., 2014). In this study, only the highest dose of RO5256390 (10 mg/kg) was able to affect responding for the chocolate pellets, while treatment with $3 \mathrm{mg} / \mathrm{kg}$ of RO5256390 did not reduce food responding. Therefore, the two mentioned studies reported dissimilar sensitivity of the drug effect at the different doses tested, which is likely attributable to differences in experimental design: Pei et al. (2014) capped daily intake at 40 pellets per session, while Ferragud et al. (2017) had no limit in responses, allowing for a more sensitive measurement of TAAR1 effects even at lower doses.

Another study, performed in mice, reported similar effects of TAAR1 agonism. R5166017 (0.3 mg/kg) was able to reduce high fat diet intake in a model of diet-induced obesity (Raab et al., 2016). Following a 10-h fast, acute injection of the
TAAR1 agonist reduced the total number of meals and duration of meals during the first hour compared to obese mice injected with vehicle as well as TAAR1 knockout (KO) mice (Raab et al., 2016). Additionally, subchronic treatment with the TAAR1 agonist (admixed in the diet to deliver an approximate dose of $3.5 \mathrm{mg} / \mathrm{kg}$ ) reduced daily intake of the high fat diet by $25 \%$ and reduced body weight by $6.6 \%$ in obese mice (Raab et al., 2016).

Interestingly, partial agonism at TAAR1 (by RO5203648 or RO5263397) has been shown to have no effects on food self-administration (Pei et al., 2014) or to enhance responding for food under a progressive ratio schedule (Pei et al., 2014, 2017). Selective TAAR1 full agonists are known to decrease the frequency of dopamine neuron firing in the VTA through activation of inwardly rectifying $\mathrm{K}^{+}$channels (Revel et al., 2011). However, partial TAAR1 agonism (Revel et al., 2012) as well as TAAR1 antagonism (Bradaia et al., 2009) have opposite effects, suggesting that TAAR1 maintains a degree of baseline or constitutive activity. Thus, while the divergence in effects on food reward between the full and partial TAAR1 agonism is not fully elucidated, we hypothesize that TAAR1 full agonist effect on binge eating lies in its ability to reduce VTA dopaminergic activity (see Figure 1).

\section{TAAR1 AGONISM REDUCES THE REINFORCING PROPERTIES OF PALATABLE FOOD-ASSOCIATED CUES}

Environmental food-associated stimuli exert a powerful control over behavior and can robustly enhance the desire to binge, even in satiated humans ( $\mathrm{Ng}$ and Davis, 2013; Boswell and Kober, 2016) and animals (Everitt and Robbins, 2005; Giuliano and Cottone, 2015; Robinson et al., 2015). There is evidence in binge eating humans and animals of increased sensitization to palatable food cues (Cowdrey et al., 2011; Dimitropoulos et al., 2012; Lawrence et al., 2012; Meule et al., 2012; Schmitz et al., 2014; Hendrikse et al., 2015; Shank et al., 2015; Smith et al., 2015; Velazquez-Sanchez et al., 2015). In humans, measures of increased sensitivity are found to be associated with increased food seeking and eating (Lawrence et al., 2012), body mass index (Shank et al., 2015), and severity of self-reported binge eating symptoms (Schmitz et al., 2014).

A procedure used in the preclinical laboratory setting to assess the magnitude of influence of a conditioned stimulus (CS) over food or drug-seeking behavior is the second-order schedule of reinforcement (Giuliano et al., 2012; Giuliano and Cottone, 2015). In this paradigm, a stimulus is paired with palatable food (or another primary reinforcer) and is able to enhance or maintain responding, even in the absence of the primary reinforcer (Everitt and Robbins, 2000). In a second-order schedule of reinforcement, sessions typically comprise of consecutive intervals with the first one occurring before presentation of the palatable food and allowing the evaluation of the conditioned reinforcing properties of cues in absence of reinforcer (Giuliano and Cottone, 2015; Velazquez-Sanchez et al., 2015). In animals with a history of binge-eating a highly palatable, sugary 


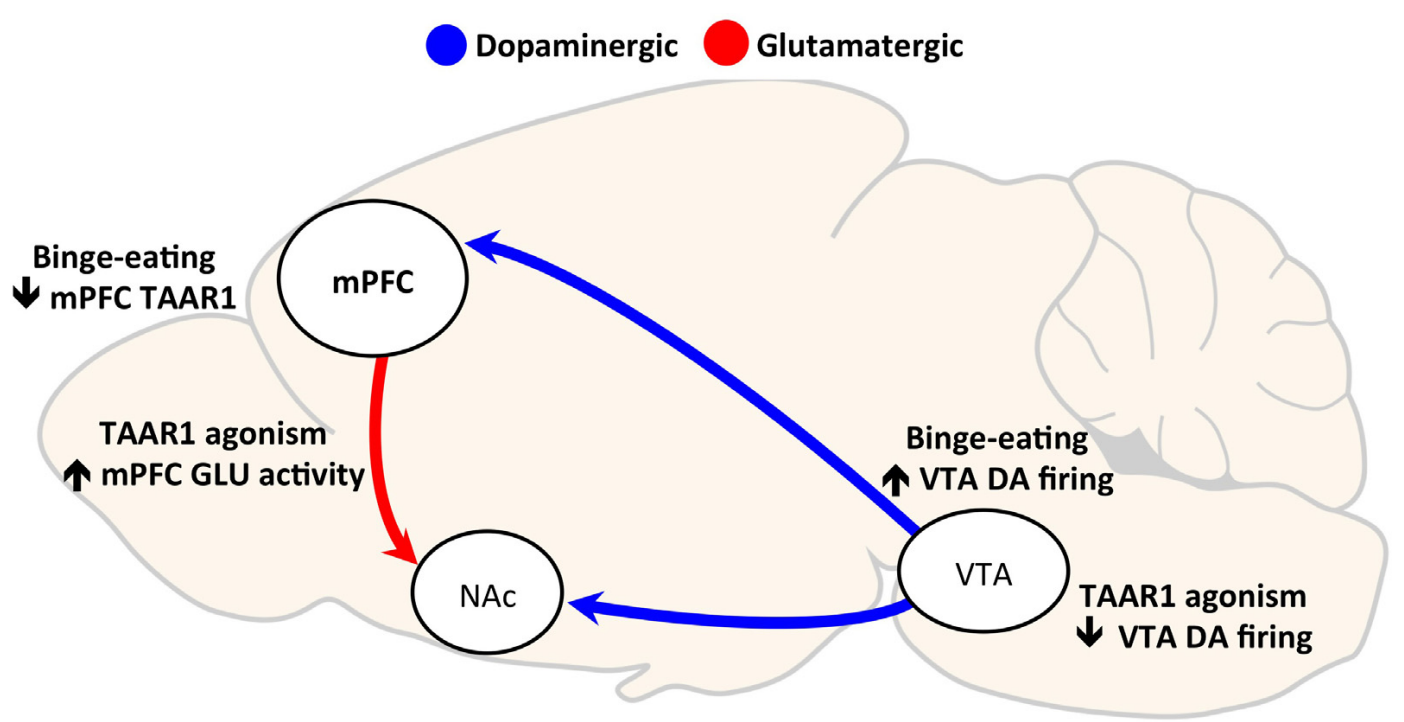

FIGURE 1 | Hypothesized mechanisms of Trace Amine Associated Receptor 1 (TAAR1) agonism effects on compulsive eating. Two hypothesized mechanisms by which TAAR1 agonism may reduce binge eating are through: (1) decreasing VTA neuronal firing, and (2) increasing glutamatergic activity in the mPFC. Binge eating of palatable food repeatedly activates the VTA to NAc dopaminergic reward pathway (Rada et al., 2005). TAAR1 agonism decreases VTA neuron firing through activation of inwardly rectifying $\mathrm{K}^{+}$channels (Revel et al., 2011, 2013); thus, its effects on reducing binge eating may be mediated by preventing hyperdopaminergic activity. Secondly, prolonged, intermittent binge eating of palatable food is a decrease in TAAR1 protein expression in the medial prefrontal cortex (mPFC) (Ferragud et al., 2017). The loss of TAAR1 has been shown to cause hypoglutamatergic function in mPFC (Espinoza et al., 2015), and low PFC activity is correlated with loss of control over eating (Balodis et al., 2013). Therefore, we hypothesize that TAAR1 agonism reduces binge, compulsive eating in part through restoring impaired mPFC activity [DA, dopamine; GLU, glutamate; mPFC, medial prefrontal cortex; NAc, nucleus accumbens; TAAR1, trace amine-associated receptor 1; VTA, ventral tegmental area].

diet, conditioned reinforcers elicit and maintain vigorous food seeking behavior as measured in a second-order schedule of reinforcement (Smith et al., 2015; Velazquez-Sanchez et al., 2015). The TAAR1 full agonist, RO5256390, was shown to block food-seeking behavior under this schedule, bringing responding to control levels (Ferragud et al., 2017). Importantly, the drug's effect on food seeking was observed during the first interval (before food ingestion occurred), suggesting an effect on the incentive value of palatable food. Furthermore, no effects were observed in animals without a history of binge eating that were responding for standard chow food.

Another paradigm used to test the rewarding properties of food or drugs and the ability of paired contextual cues to drive behavior is the conditioned place preference (CPP) test. In animals with a history of binge-eating a highly palatable, sugary diet, following conditioning, tactile and visual cues associated with the highly palatable food are able to induce a strong place preference, unlike stimuli associated to the standard chow diet (Velazquez-Sanchez et al., 2015; Ferragud et al., 2017). When given prior to the CPP test, RO5256390 fully and selectively blocked the expression of CPP (Ferragud et al., 2017).

These experiments show that TAAR1 agonism greatly reduced the strength of palatable-food associated stimuli in driving behavior in rats with a history of binge eating. Though exact mechanisms have not yet been examined specifically for palatable food-cues, studies have found that the ability of TAAR1 to decrease the ability of drug-paired cues to elicit cocaine-seeking behavior can be pinpointed the ventral tegmental area and the prelimbic region of the medial prefrontal cortex (mPFC) as critical sites of action for TAAR1 in reducing cue-induced seeking behavior and drug-related memory expression (Liu et al., 2016, 2017).

\section{TAAR1 AGONISM BLOCKS COMPULSIVE-LIKE EATING}

Compulsivity is a behavioral construct observed in different disorders, including drug addiction and disorders of pathological eating, where there is a loss of control over behavior that results in continued use despite incurring negative consequences (e.g., medical, psychological, emotional, and social impairment) (Cottone et al., 2012; American Psychiatric Association, 2013; Rossetti et al., 2014; Velazquez-Sanchez et al., 2014; Smith et al., 2015; Moore et al., 2017c). Compulsive eating behavior is characteristic of certain forms of obesity, BED, BN, certain forms of AN, and food addiction (de Zwaan, 2001; Davis and Carter, 2009; Gearhardt et al., 2009; American Psychiatric Association, 2013; Davis, 2013b; Volkow et al., 2013; HoneBlanchet and Fecteau, 2014). Compulsive eating behavior has been dissected into three functional domains: habitual overeating, eating to alleviate a negative emotional state, and overeating despite negative consequences (Moore et al., 2017a,b,c), engendered by maladaptive habit formation (Furlong et al., 2014), the emergence of a negative affect (Cottone 
et al., 2009; Blasio et al., 2013; Iemolo et al., 2013), and a failure of inhibitory control systems (Velazquez-Sanchez et al., 2015; Nieh et al., 2015; Myers, 2017), respectively. 'Loss of control' is thought to result from deficits in inhibitory control mechanisms responsible for the suppression of inappropriate actions. These deficits confer vulnerability to the addictive behavior and/or emerge from persistent and prolonged palatable food overconsumption (Volkow et al., 2013; Velazquez-Sanchez et al., 2014).

To test continued overeating despite consequences in animals, a commonly used paradigm is the light/dark conflict test, where feeding is typically suppressed in control rats when they face the aversive bright compartment of the light/dark box. However, rats with a history of intermittent access to palatable food will compulsively consume the palatable diet in face of the risky environment (Cottone et al., 2012; Dore et al., 2014; VelazquezSanchez et al., 2014; Smith et al., 2015). TAAR1 activation was shown to fully block compulsive eating of palatable food, reducing intake in the bright compartment by $75 \%$, compared to vehicle treatment (Ferragud et al., 2017). Importantly, the study confidently excluded the alternative interpretation that drug's effect was induced by a potential anxiogenic profile as RO5256390 exerted no effect on anxiety-like behavior in a defensive withdrawal test (Ferragud et al., 2017).

Compulsivity shares some commonalities with impulsivity in that both constructs involve a dysfunction in inhibitory control, mediated by frontal cortex projections to subcortical regions (Robbins et al., 2012). Dysfunctions in inhibitory control can manifest as impulsive-like behavior, are hypothesized to contribute to the emergence of compulsive drug use and compulsive eating (Belin et al., 2008; Dalley et al., 2011; Velazquez-Sanchez et al., 2014), and are thought to be caused or exacerbated by exposure to drugs of abuse and highly palatable food (Jentsch and Taylor, 1999; Vickers et al., 2017). TAAR1 has been linked to impulsive-like behavior, likely through modulation of prefrontal glutamatergic neurotransmission. Deletion of TAAR1 in mice reduced prefrontal glutamatergic activity, coupled with heightened impulsive-like behavior, determined as high premature and inter-trial interval responding in a Fixed Interval-Peak Interval test (Espinoza et al., 2015). While TAAR1 partial agonism had no effects in TAAR1 KO mice, control mice treated with RO5203648 displayed decreased premature correct responses in an FI-30 schedule of reinforcement task (Espinoza et al., 2015), a measure of impulsive-like behavior (Berger and Sagvolden, 1998). Thus, TAAR1 effects on impulsive-like behavior are hypothesized to be attributable to the modulation of the prefrontal glutamatergic signaling that is critical to inhibitory control processes and is dysregulated in addiction (van Huijstee and Mansvelder, 2014). Furthermore, in a primate model, TAAR1 agonism reduced impulsivity and increased cognitive flexibility (Revel et al., 2013), another component of executive function that is often impaired in addiction and in disorders of compulsivity (Banca et al., 2016). Thus, we hypothesize that TAAR1 effects on compulsive eating may be mediated in part through a restoration of deficits in inhibitory control functions through restoring prefrontocortical glutamate activity (see Figure 1).

\section{BINGE-LIKE EATING DECREASES TAAR1 PROTEIN EXPRESSION IN PREFRONTAL CORTICES}

Inhibitory control processes are largely governed by prefrontocortical circuits, and dysfunctions in this pathway are thought to underlie the loss of control and continued intake despite aversive consequences (Tomasi and Volkow, 2013; Volkow et al., 2013; Moore et al., 2017a,b,c). Decreased activity in the prefrontal cortex (PFC) is observed in obesity, and is associated with decreased inhibitory control (Volkow and Wise, 2005).

Trace Amine Associated Receptor 1 modulation of prefrontocortical activity is one hypothesized mechanism for the effects on compulsive eating and other addictive behaviors. TAAR1 protein expression was decreased in the mPFC of animals with a history of binge eating of palatable food, compared to controls fed a standard chow diet (Ferragud et al., 2017). As summarized above, binge-like eating rats also display compulsive-like eating behavior, which is fully blocked by pretreatment with the full agonist of TAAR1 RO5256390 (Ferragud et al., 2017). Therefore, based on these results, we hypothesize that the RO5256390 may be able to restore the loss of function in prefrontocortical TAAR1 transmission, which is responsible for the observed compulsive, binge eating (see Figure 1). In line with this hypothesis, TAAR1 KO mice display behaviors consistent with prefrontal dysfunctions, such as perseverative behavior and impulsivity, suggesting that a deficiency in TAAR1 may result in deficits in cognitive function and behavioral flexibility (Espinoza et al., 2015). Furthermore, intra-mPFC (specifically infralimbic, IL, but not prelimbic, PrL) administration of the TAAR1 agonist decreased binge-like eating without affecting the intake of regular chow (Ferragud et al., 2017). While TAAR1 mRNA expression is equivalent in the IL and PrL (Liu et al., 2017), the IL cortex is crucial for the development and expression of inflexible reward seeking as well as habitual behavior (Barker et al., 2014; Moorman et al., 2015). However, it is likely that other TAAR1-expressing brain areas contribute to the systemic effects of TAAR1 agonism, as the magnitude of food intake reduction following intraIL RO5256390 microinfusion was lower than that observed following intraperitoneal administration (Ferragud et al., 2017). It is not yet known if TAAR1 expression patterns are altered in obesity or other paradigms of overeating, or if this effect is specific to binge eating behavior.

\section{DISCUSSION AND CONCLUSIONS}

The rise of eating-related disorders, including some forms of obesity, BED, BN, AN, and food addiction has prompted much research, and has resulted in a few medications with varying levels of effectiveness (Reas and Grilo, 2014). However, many patients constantly relapse in symptoms that include binge and compulsive eating, failing to achieve significant health and psychological benefits (Ferguson and Spitzer, 1995; Reas and Grilo, 2014). As TAAR1 agonism has been shown to reduce 
various maladaptive eating behaviors, it can indeed be regarded as a very promising therapeutic target for compulsive eating behavior, even though much more research is needed at this point. Recently, Lisdexamfetamine (LDX) was approved for the treatment of BED, and has been shown to reduce binge eating behaviors as well as compulsive eating behaviors (assessed with the Yale-Brown Obsessive Compulsive Scale modified for Binge Eating; Y-BOCS-BE) (Hudson et al., 2017). Interestingly, TAAR1 is also activated by amphetamine (Borowsky et al., 2001), the active metabolite in LDX (Goodman, 2010). LDX and TAAR1 agonism may, therefore, work through similar mechanisms to restore dysfunctional signaling in prefrontal areas, alleviating impaired inhibitory behaviors.

Importantly, TAAR1 effects on compulsive, binge eating are being driven by direct actions on food reward mechanisms, rather than homeostatic needs. Evidence for this is twofold. The first is that no food restriction or deprivation was used in the abovesummarized studies showing its efficacy (Pei et al., 2014; Ferragud et al., 2017). Second, in a control experiment in food deprived rats, TAAR1 agonism had no effect on food intake at doses which reduced palatable food binging (Ferragud et al., 2017). Thus, agonism of TAAR1 specifically disrupted responding for palatable food, but not standard chow (in either ad libitum fed or food-restricted rats).

Though TAAR1 agonism effects on binge, compulsive eating are not being mediated by homeostatic mechanisms, it is interesting to note that TAAR1 activation has been studied for its metabolic effects in models of obesity and diabetes (Raab et al., 2016). In the periphery, TAAR1 agonism has been shown to have incretin-like effects, reducing high-fat food intake and body weight in diet-induced obesity mice, as well as normalizing glucose levels and restoring insulin sensitivity in diabetic mice (Raab et al., 2016). Considering the high occurrence of compulsive eating behavior with obesity (Dingemans and van Furth, 2012; Davis, 2013a), and that obesity greatly increases risk for diabetes (World Health Organization, 2000), TAAR1 agonism

\section{REFERENCES}

American Psychiatric Association (2013). Diagnostic and Statistical Manual of Mental Disorders. Washington, DC: American Psychiatric Association. doi: 10.1176/appi.books.9780890425596

Avena, N. M., Rada, P., and Hoebel, B. G. (2008). Evidence for sugar addiction: behavioral and neurochemical effects of intermittent, excessive sugar intake. Neurosci. Biobehav. Rev. 32, 20-39. doi: 10.1016/j.neubiorev.2007. 04.019

Balodis, I. M., Molina, N. D., Kober, H., Worhunsky, P. D., White, M. A., Rajita, S., et al. (2013). Divergent neural substrates of inhibitory control in binge eating disorder relative to other manifestations of obesity. Obesity 21, 367-377. doi: 10.1002/oby.20068

Banca, P., Harrison, N. A., and Voon, V. (2016). Compulsivity across the pathological misuse of drug and non-drug rewards. Front. Behav. Neurosci. 10:154. doi: 10.3389/fnbeh.2016.00154

Barker, J. M., Taylor, J. R., and Chandler, L. J. (2014). A unifying model of the role of the infralimbic cortex in extinction and habits. Learn. Mem. 21, 441-448. doi: $10.1101 / \mathrm{lm} .035501 .114$

Belin, D., Mar, A. C., Dalley, J. W., Robbins, T. W., and Everitt, B. J. (2008). High impulsivity predicts the switch to compulsive cocaine-taking. Science 320, 1352-1355. doi: 10.1126/science.1158136 may act to reduce the amount of food eaten, but also to alleviate the comorbid metabolic symptoms that result from overeating.

The TAAR1 full agonist RO5256390 was not found to have any effects on anxiety-like (Ferragud et al., 2017) or depressive-like behavior (Revel et al., 2013; Ferragud et al., 2017). TAAR1's specific effects of treating compulsive eating behavior without necessarily having effects on mood or emotion, highlights the multifaceted and parallel processes that lead to behavioral expression of compulsive eating. It is important to note that investigation into TAAR1 effects on food addiction mechanisms is in its nascent stages, with the majority of evidence coming from a few studies. Much more research is needed, including assessment of clinical efficacy in heterogeneous human populations. The targeting of specific cognitive processes, such as food cue reinforcement and inhibitory control mechanisms, will hopefully lead to more effective treatment strategies for compulsive eating and other addictive behaviors.

\section{AUTHOR CONTRIBUTIONS}

All authors listed have made a substantial, direct and intellectual contribution to the work, and approved it for publication.

\section{FUNDING}

This work was supported by the National Institutes of Health [Grant Nos. DA030425 (PC), MH091945 (PC), MH093650 (VS), AA024439 (VS), AA025038 (VS), and DA044664 (CM)]; the Peter Paul Career Development Professorships (PC); the McManus Charitable Trust (VS); and the Burroughs Wellcome Fund (CM) through the Transformative Training Program in Addiction Sciences [Grant No. 1011479]. Its contents are solely the responsibility of the authors and do not necessarily represent the official views of the National Institutes of Health.

Berger, D. F., and Sagvolden, T. (1998). Sex differences in operant discrimination behaviour in an animal model of attention-deficit hyperactivity disorder. Behav. Brain Res. 94, 73-82. doi: 10.1016/S0166-4328(97)00171-X

Blasio, A., Iemolo, A., Sabino, V., Petrosino, S., Steardo, L., Rice, K. C., et al. (2013). Rimonabant precipitates anxiety in rats withdrawn from palatable food: role of the central amygdala. Neuropsychopharmacology 38, 2498-2507. doi: 10.1038/npp.2013.153

Borowsky, B., Adham, N., Jones, K. A., Raddatz, R., Artymyshyn, R., Ogozalek, K. L., et al. (2001). Trace amines: identification of a family of mammalian G protein-coupled receptors. Proc. Natl. Acad. Sci. U.S.A. 98, 8966-8971. doi: 10.1073/pnas.151105198

Boswell, R. G., and Kober, H. (2016). Food cue reactivity and craving predict eating and weight gain: a meta-analytic review. Obes. Rev. 17, 159-177. doi: 10.1111/obr.12354

Bradaia, A., Trube, G., Stalder, H., Norcross, R. D., Ozmen, L., Wettstein, J. G., et al. (2009). The selective antagonist EPPTB reveals TAAR1-mediated regulatory mechanisms in dopaminergic neurons of the mesolimbic system. Proc. Natl. Acad. Sci. U.S.A. 106, 20081-20086. doi: 10.1073/pnas.090652 2106

Corwin, R. L., Avena, N. M., and Boggiano, M. M. (2011). Feeding and reward: perspectives from three rat models of binge eating. Physiol. Behav. 104, 87-97. doi: 10.1016/j.physbeh.2011.04.041 
Cottone, P., Sabino, V., Roberto, M., Bajo, M., Pockros, L., Frihauf, J. B., et al. (2009). CRF system recruitment mediates dark side of compulsive eating. Proc. Natl. Acad. Sci. U.S.A. 106, 20016-20020. doi: 10.1073/pnas.0908789106

Cottone, P., Sabino, V., Steardo, L., and Zorrilla, E. P. (2008). Opioid-dependent anticipatory negative contrast and binge-like eating in rats with limited access to highly preferred food. Neuropsychopharmacology 33, 524-535. doi: 10.1038/ sj.npp. 1301430

Cottone, P., Wang, X., Park, J. W., Valenza, M., Blasio, A., Kwak, J., et al. (2012). Antagonism of sigma-1 receptors blocks compulsivelike eating. Neuropsychopharmacology 37, 2593-2604. doi: 10.1038/npp. 2012.89

Cowdrey, F. A., Park, R. J., Harmer, C. J., and McCabe, C. (2011). Increased neural processing of rewarding and aversive food stimuli in recovered anorexia nervosa. Biol. Psychiatry 70, 736-743. doi: 10.1016/j.biopsych.2011.05.028

Dalley, J. W., Everitt, B. J., and Robbins, T. W. (2011). Impulsivity, compulsivity, and top-down cognitive control. Neuron 69, 680-694. doi: 10.1016/j.neuron. 2011.01.020

Davis, C. (2013a). From passive overeating to "food addiction": a spectrum of compulsion and severity. ISRN Obes. 2013:435027. doi: 10.1155/2013/435027

Davis, C. (2013b). A narrative review of binge eating and addictive behaviors: shared associations with seasonality and personality factors. Front. Psychiatry 4:183. doi: 10.3389/fpsyt.2013.00183

Davis, C., and Carter, J. C. (2009). Compulsive overeating as an addiction disorder. A review of theory and evidence. Appetite 53, 1-8. doi: 10.1016/j.appet.2009.05.018

de Zwaan, M. (2001). Binge eating disorder and obesity. Int. J. Obes. Relat. Metab. Disord. 25(Suppl. 1), S51-S55. doi: 10.1038/sj.ijo.0801699

Dimitropoulos, A., Tkach, J., Ho, A., and Kennedy, J. (2012). Greater corticolimbic activation to high-calorie food cues after eating in obese vs. normal-weight adults. Appetite 58, 303-312. doi: 10.1016/j.appet.2011.10.014

Dingemans, A. E., and van Furth, E. F. (2012). Binge Eating Disorder psychopathology in normal weight and obese individuals. Int. J. Eat. Disord. 45, 135-138. doi: 10.1002/eat.20905

Dore, R., Valenza, M., Wang, X., Rice, K. C., Sabino, V., and Cottone, P. (2014). The inverse agonist of CB1 receptor SR141716 blocks compulsive eating of palatable food. Addict. Biol. 19, 849-861. doi: 10.1111/adb.12056

Espinoza, S., Lignani, G., Caffino, L., Maggi, S., Sukhanov, I., Leo, D., et al. (2015). TAAR1 modulates cortical glutamate NMDA receptor function. Neuropsychopharmacology 40, 2217-2227. doi: 10.1038/npp.2015.65

Everitt, B. J., and Robbins, T. W. (2000). Second-order schedules of drug reinforcement in rats and monkeys: measurement of reinforcing efficacy and drug-seeking behaviour. Psychopharmacology 153, 17-30. doi: 10.1007/ s002130000566

Everitt, B. J., and Robbins, T. W. (2005). Neural systems of reinforcement for drug addiction: from actions to habits to compulsion. Nat. Neurosci. 8, 1481-1489. doi: $10.1038 / \mathrm{nn} 1579$

Ferguson, K. J., and Spitzer, R. L. (1995). Binge eating disorder in a community-based sample of successful and unsuccessful dieters. Int. J. Eat. Disord. 18, 167-172.

Ferragud, A., Howell, A. D., Moore, C. F., Ta, T. L., Hoener, M. C., Sabino, V., et al. (2017). The trace amine-associated receptor 1 agonist RO5256390 blocks compulsive, binge-like eating in rats. Neuropsychopharmacology 42, 1458-1470. doi: 10.1038/npp.2016.233

Flament, M. F., Bissada, H., and Spettigue, W. (2012). Evidence-based pharmacotherapy of eating disorders. Int. J. Neuropsychopharmacol. 15, 189-207. doi: 10.1017/S1461145711000381

Furlong, T. M., Jayaweera, H. K., Balleine, B. W., and Corbit, L. H. (2014). Bingelike consumption of a palatable food accelerates habitual control of behavior and is dependent on activation of the dorsolateral striatum. J. Neurosci. 34, 5012-5022. doi: 10.1523/JNEUROSCI.3707-13.2014

Gearhardt, A. N., Corbin, W. R., and Brownell, K. D. (2009). Preliminary validation of the Yale Food Addiction Scale. Appetite 52, 430-436. doi: 10.1016/j.appet. 2008.12.003

Giuliano, C., and Cottone, P. (2015). The role of the opioid system in binge eating disorder. CNS Spectr. 20, 537-545. doi: 10.1017/S10928529150 00668

Giuliano, C., Robbins, T. W., Nathan, P. J., Bullmore, E. T., and Everitt, B. J. (2012). Inhibition of opioid transmission at the $\mu$-opioid receptor prevents both food seeking and binge-like eating. Neuropsychopharmacology 37, 2643-2652. doi: $10.1038 /$ npp. 2012.128

Goodman, D. W. (2010). Lisdexamfetamine dimesylate (vyvanse), a prodrug stimulant for attention-deficit/hyperactivity disorder. P T 35, 273-287.

Harkness, J. H., Shi, X., Janowsky, A., and Phillips, T. J. (2015). Trace amine-associated receptor 1 regulation of methamphetamine intake and related traits. Neuropsychopharmacology 40, 2175-2184. doi: 10.1038/npp. 2015.61

Hendrikse, J. J., Cachia, R. L., Kothe, E. J., McPhie, S., Skouteris, H., and Hayden, M. J. (2015). Attentional biases for food cues in overweight and individuals with obesity: a systematic review of the literature. Obes. Rev. 16, 424-432. doi: 10.1111/obr.12265

Hone-Blanchet, A., and Fecteau, S. (2014). Overlap of food addiction and substance use disorders definitions: analysis of animal and human studies. Neuropharmacology 85, 81-90. doi: 10.1016/j.neuropharm.2014.05.019

Hudson, J. I., McElroy, S. L., Ferreira-Cornwell, M. C., Radewonuk, J., and Gasior, M. (2017). Efficacy of lisdexamfetamine in adults with moderate to severe binge-eating disorder: a randomized clinical trial. JAMA Psychiatry 74, 903-910. doi: 10.1001/jamapsychiatry.2017.1889

Iemolo, A., Blasio, A., St Cyr, S. A., Jiang, F., Rice, K. C., Sabino, V., et al. (2013). CRF-CRF1 receptor system in the central and basolateral nuclei of the amygdala differentially mediates excessive eating of palatable food. Neuropsychopharmacology 38, 2456-2466. doi: 10.1038/npp.2013.147

Jentsch, J. D., and Taylor, J. R. (1999). Impulsivity resulting from frontostriatal dysfunction in drug abuse: implications for the control of behavior by reward-related stimuli. Psychopharmacology 146, 373-390. doi: 10.1007/ PL00005483

Lawrence, N. S., Hinton, E. C., Parkinson, J. A., and Lawrence, A. D. (2012). Nucleus accumbens response to food cues predicts subsequent snack consumption in women and increased body mass index in those with reduced self-control. Neuroimage 63, 415-422. doi: 10.1016/j.neuroimage.2012.06.070

Lehnert, T., Sonntag, D., Konnopka, A., Riedel-Heller, S., and Konig, H. H. (2013). Economic costs of overweight and obesity. Best Pract. Res. Clin. Endocrinol. Metab. 27, 105-115. doi: 10.1016/j.beem.2013.01.002

Liu, J. F., Siemian, J. N., Seaman, R. Jr., Zhang, Y., and Li, J. X. (2017). Role of TAAR1 within the subregions of the mesocorticolimbic dopaminergic system in cocaine-seeking behavior. J. Neurosci. 37, 882-892. doi: 10.1523/JNEUROSCI. 2006-16.2016

Liu, J. F., Thorn, D. A., Zhang, Y., and Li, J. X. (2016). Effects of trace amine-associated receptor 1 agonists on the expression, reconsolidation, and extinction of cocaine reward memory. Int. J. Neuropsychopharmacol. 19:pyw009. doi: 10.1093/ijnp/pyw009

Meule, A., Lutz, A., Vogele, C., and Kubler, A. (2012). Women with elevated food addiction symptoms show accelerated reactions, but no impaired inhibitory control, in response to pictures of high-calorie food-cues. Eat. Behav. 13, 423-428. doi: 10.1016/j.eatbeh.2012.08.001

Miller, G. M., Verrico, C. D., Jassen, A., Konar, M., Yang, H., Panas, H., et al. (2005). Primate trace amine receptor 1 modulation by the dopamine transporter. J. Pharmacol. Exp. Ther. 313, 983-994. doi: 10.1124/jpet.105.084459

Moore, C. F., Panciera, J. I., Sabino, V., and Cottone, P. (2017a). Neuropharmacology of compulsive eating. Philos. Trans. R. Soc. Lond. B Biol. Sci. 373:20170024. doi: 10.1098/rstb.2017.0024

Moore, C. F., Sabino, V., Koob, G. F., and Cottone, P. (2017b). Neuroscience of compulsive eating behavior. Front. Neurosci. 11:469. doi: 10.3389/fnins.2017. 00469

Moore, C. F., Sabino, V., Koob, G. F., and Cottone, P. (2017c). Pathological overeating: emerging evidence for a compulsivity construct. Neuropsychopharmacology 42, 1375-1389. doi: 10.1038/npp.2016.269

Moorman, D. E., James, M. H., McGlinchey, E. M., and Aston-Jones, G. (2015). Differential roles of medial prefrontal subregions in the regulation of drug seeking. Brain Res. 1628(Pt A), 130-146. doi: 10.1016/j.brainres.2014.12.024

Morris, M. J., Beilharz, J. E., Maniam, J., Reichelt, A. C., and Westbrook, R. F. (2015). Why is obesity such a problem in the 21 st century? The intersection of palatable food, cues and reward pathways, stress, and cognition. Neurosci. Biobehav. Rev. 58, 36-45. doi: 10.1016/j.neubiorev.2014.12.002

Myers, K. P. (2017). Sensory-specific satiety is intact in rats made obese on a highfat high-sugar choice diet. Appetite 112, 196-200. doi: 10.1016/j.appet.2017. 01.013 
Ng, L., and Davis, C. (2013). Cravings and food consumption in Binge Eating Disorder. Eat. Behav. 14, 472-475. doi: 10.1016/j.eatbeh.2013. 08.011

Nieh, E. H., Matthews, G. A., Allsop, S. A., Presbrey, K. N., Leppla, C. A., Wichmann, R., et al. (2015). Decoding neural circuits that control compulsive sucrose seeking. Cell 160, 528-541. doi: 10.1016/j.cell.2015.01.003

Pei, Y., Asif-Malik, A., Hoener, M., and Canales, J. J. (2017). A partial trace amine-associated receptor 1 agonist exhibits properties consistent with a methamphetamine substitution treatment. Addict. Biol. 22, 1246-1256. doi: $10.1111 / \mathrm{adb} .12410$

Pei, Y., Lee, J., Leo, D., Gainetdinov, R. R., Hoener, M. C., and Canales, J. J. (2014). Activation of the trace amine-associated receptor 1 prevents relapse to cocaine seeking. Neuropsychopharmacology 39, 2299-2308. doi: 10.1038/npp. 2014.88

Pei, Y., Mortas, P., Hoener, M. C., and Canales, J. J. (2015). Selective activation of the trace amine-associated receptor 1 decreases cocaine's reinforcing efficacy and prevents cocaine-induced changes in brain reward thresholds. Prog. Neuropsychopharmacol. Biol. Psychiatry 63, 70-75. doi: 10.1016/j.pnpbp. 2015. 05.014

Raab, S., Wang, H., Uhles, S., Cole, N., Alvarez-Sanchez, R., Kunnecke, B., et al. (2016). Incretin-like effects of small molecule trace amine-associated receptor 1 agonists. Mol. Metab. 5, 47-56. doi: 10.1016/j.molmet.2015.09.015

Rada, P., Avena, N. M., and Hoebel, B. G. (2005). Daily bingeing on sugar repeatedly releases dopamine in the accumbens shell. Neuroscience 134, 737-744. doi: 10.1016/j.neuroscience.2005.04.043

Reas, D. L., and Grilo, C. M. (2014). Current and emerging drug treatments for binge eating disorder. Expert Opin. Emerg. Drugs 19, 99-142. doi: 10.1517/ 14728214.2014.879291

Revel, F. G., Moreau, J. L., Gainetdinov, R. R., Bradaia, A., Sotnikova, T. D., Mory, R., et al. (2011). TAAR1 activation modulates monoaminergic neurotransmission, preventing hyperdopaminergic and hypoglutamatergic activity. Proc. Natl. Acad. Sci. U.S.A. 108, 8485-8490. doi: 10.1073/pnas. 1103029108

Revel, F. G., Moreau, J. L., Gainetdinov, R. R., Ferragud, A., VelazquezSanchez, C., Sotnikova, T. D., et al. (2012). Trace amine-associated receptor 1 partial agonism reveals novel paradigm for neuropsychiatric therapeutics. Biol. Psychiatry 72, 934-942. doi: 10.1016/j.biopsych.2012.05.014

Revel, F. G., Moreau, J. L., Pouzet, B., Mory, R., Bradaia, A., Buchy, D., et al. (2013). A new perspective for schizophrenia: TAAR1 agonists reveal antipsychotic- and antidepressant-like activity, improve cognition and control body weight. Mol. Psychiatry 18, 543-556. doi: 10.1038/mp.2012.57

Robbins, T. W., Curran, H. V., and de Wit, H. (2012). Special issue on impulsivity and compulsivity. Psychopharmacology 219, 251-252. doi: 10.1007/s00213-0112584- $\mathrm{x}$

Robinson, M. J., Burghardt, P. R., Patterson, C. M., Nobile, C. W., Akil, H., Watson, S. J., et al. (2015). Individual differences in cue-induced motivation and striatal systems in rats susceptible to diet-induced obesity. Neuropsychopharmacology 40, 2113-2123. doi: 10.1038/npp.2015.71

Rossetti, C., Spena, G., Halfon, O., and Boutrel, B. (2014). Evidence for a compulsive-like behavior in rats exposed to alternate access to highly preferred palatable food. Addict. Biol. 19, 975-985. doi: 10.1111/adb. 12065

Schmitz, F., Naumann, E., Trentowska, M., and Svaldi, J. (2014). Attentional bias for food cues in binge eating disorder. Appetite 80, 70-80. doi: 10.1016/j.appet. 2014.04.023

Shank, L. M., Tanofsky-Kraff, M., Nelson, E. E., Shomaker, L. B., Ranzenhofer, L. M., Hannallah, L. M., et al. (2015). Attentional bias to food cues in youth with loss of control eating. Appetite 87, 68-75. doi: 10.1016/j.appet.2014. 11.027

Smith, K. L., Rao, R. R., Velazquez-Sanchez, C., Valenza, M., Giuliano, C., Everitt, B. J., et al. (2015). The uncompetitive N-methyl-D-aspartate antagonist memantine reduces binge-like eating, food-seeking behavior, and compulsive eating: role of the nucleus accumbens shell. Neuropsychopharmacology 40, 1163-1171. doi: 10.1038/npp.2014.299

Thorn, D. A., Jing, L., Qiu, Y., Gancarz-Kausch, A. M., Galuska, C. M., Dietz, D. M., et al. (2014). Effects of the trace amine-associated receptor 1 agonist RO5263397 on abuse-related effects of cocaine in rats. Neuropsychopharmacology 39, 2309-2316. doi: 10.1038/npp.2014.91

Tomasi, D., and Volkow, N. D. (2013). Striatocortical pathway dysfunction in addiction and obesity: differences and similarities. Crit. Rev. Biochem. Mol. Biol. 48, 1-19. doi: 10.3109/10409238.2012.735642

van Huijstee, A. N., and Mansvelder, H. D. (2014). Glutamatergic synaptic plasticity in the mesocorticolimbic system in addiction. Front. Cell. Neurosci. 8:466. doi: 10.3389/fncel.2014.00466

Velazquez-Sanchez, C., Ferragud, A., Moore, C. F., Everitt, B. J., Sabino, V., and Cottone, P. (2014). High trait impulsivity predicts food addiction-like behavior in the rat. Neuropsychopharmacology 39, 2463-2472. doi: 10.1038/npp.2014.98

Velazquez-Sanchez, C., Santos, J. W., Smith, K. L., Ferragud, A., Sabino, V., and Cottone, P. (2015). Seeking behavior, place conditioning, and resistance to conditioned suppression of feeding in rats intermittently exposed to palatable food. Behav. Neurosci. 129, 219-224. doi: 10.1037/bne0000042

Vickers, S. P., Goddard, S., Brammer, R. J., Hutson, P. H., and Heal, D. J. (2017). Investigation of impulsivity in binge-eating rats in a delay-discounting task and its prevention by the d-amphetamine prodrug, lisdexamfetamine. J. Psychopharmacol. 31, 784-797. doi: 10.1177/0269881117691672

Volkow, N. D., Wang, G. J., Tomasi, D., and Baler, R. D. (2013). The addictive dimensionality of obesity. Biol. Psychiatry $73,811-818$. doi: $10.1016 /$ j.biopsych. 2012.12.020

Volkow, N. D., and Wise, R. A. (2005). How can drug addiction help us understand obesity? Nat. Neurosci. 8, 555-560. doi: 10.1038/nn1452

Whiteford, H. A., Degenhardt, L., Rehm, J., Baxter, A. J., Ferrari, A. J., Erskine, H. E., et al. (2013). Global burden of disease attributable to mental and substance use disorders: findings from the Global Burden of Disease Study 2010. Lancet 382, 1575-1586. doi: 10.1016/S0140-6736(13)61611-6

World Health Organization (2000). Obesity: Preventing and Managing the Global Epidemic. Report of a WHO consultation. WHO Technical Report Series 894. Geneva: World Health Organization.

Xie, Z., Westmoreland, S. V., Bahn, M. E., Chen, G. L., Yang, H., Vallender, E. J., et al. (2007). Rhesus monkey trace amine-associated receptor 1 signaling: enhancement by monoamine transporters and attenuation by the D2 autoreceptor in vitro. J. Pharmacol. Exp. Ther. 321, 116-127. doi: 10.1124/jpet. 106.116863

Conflict of Interest Statement: The authors declare that the research was conducted in the absence of any commercial or financial relationships that could be construed as a potential conflict of interest.

Copyright (c) 2018 Moore, Sabino and Cottone. This is an open-access article distributed under the terms of the Creative Commons Attribution License (CC BY). The use, distribution or reproduction in other forums is permitted, provided the original author(s) and the copyright owner are credited and that the original publication in this journal is cited, in accordance with accepted academic practice. No use, distribution or reproduction is permitted which does not comply with these terms. 